\title{
Prospective study on sonographic measurement of umbilical cord thickness, foetal fat layer, interventricular septal thickness as predictors of macrosomia in fetus of women with gestational diabetes mellitus
}

\author{
Janani N., D. Vimala, N. Gayathri*
}

Department of Obstetrics and Gynecology, Vinayaka Mission's Kirupananda Variyar Medical College and Hospital, Salem, Tamil Nadu, India

Received: 03 March 2018

Accepted: 28 March 2018

\section{*Correspondence:}

Dr. Janani N.,

E-mail: jananiramanesh@gmail.com

Copyright: () the author(s), publisher and licensee Medip Academy. This is an open-access article distributed under the terms of the Creative Commons Attribution Non-Commercial License, which permits unrestricted non-commercial use, distribution, and reproduction in any medium, provided the original work is properly cited.

\begin{abstract}
Background: The objectives of the study were to evaluate the Prediction of foetal macrosomia based on sonographic measurements of foetal fat layer, Interventricular septal thickness and umbilical cord thickness in Gestational Diabetes Mellitus at term.

Methods: After assessment of inclusion and exclusion criteria 100 antenatal women of gestational age more than 37 weeks selected for study in the Department of Obstetrics and Gynaecology of Vinayaka Mission's Kirupananda variyar medical college and hospital, Salem. Participants underwent a third trimester scan and three extra measurements i.e. Umbilical cord thickness, Interventricular septal thickness and foetal fat layer are measured in addition to the normal examination.

Results: In present study umbilical cord thickness had good sensitivity and negative predictive value. Hence, if umbilical cord thickness is less than 90th centile the chance of macrosomia is less, the cut off of foetal fat layer $\geq 5$ $\mathrm{mm}$ as predictor of macrosomia had sensitivity of $84.2 \%$ and specificity of $86.4 \%$ and cut off of Interventricular septal thickness $\geq 3.9 \mathrm{~mm}$ as a predictor of macrosomia had sensitivity of $84.2 \%$, specificity of $64.2 \%$, negative predictive value of $95.9 \%$. Thus, interventricular septal thickness and foetal fat layer is a reliable predictor of macrosomia.

Conclusions: From this study authors concluded that Umbilical cord thickness, foetal fat layer and Interventricular septal thickness are good predictors of foetal macrosomia. In the assessment of risk of macrosomia in addition to the ultrasonographic measurements the clinical risk factors must be considered.
\end{abstract}

Keywords: Foetal fat layer, Interventricular septal thickness, Macrosomia, Umbilical cord thickness

\section{INTRODUCTION}

Gestational Diabetes mellitus is one of the commonest problems encountered in pregnancy. According to world Health organisation estimates, India has the highest number of cases of Diabetes in the world. An estimated number of 31.7 million people with in 2000 in India are projected to increase to 79.4 million in $2030 .{ }^{1}$ It affects both mother and foetus in many ways. Infant of diabetic mother are prone for macrosomia which is a major cause of foetal and maternal morbidity.

Gestational diabetes mellitus is defined as "any degree of glucose intolerance with onset or first recognition during pregnancy", irrespective of the gestational age at which it was diagnosed. Macrosomia is defined as birth weight more than 90th percentile or more than $2 \mathrm{SD}$ for the gestational age or more than $4000 \mathrm{~g} .^{2}$ 
Pregnancy is a diabetogenic state. The high levels of maternal and placental hormones, particularly; human chorionic somatomammotropin, oestrogen, progesterone, prolactin and cortisol are implicated in the development of this gestational insulin resistance. The net effect of all these changes is a lowering of maternal fasting blood glucose levels, but a sustained and significant increase in postprandial glucose levels.

Macrosomic foetus are at risk for range of complications at birth like shoulder dystocia, obstructed labour, brachial plexus injury, skeletal injuries in foetus. ${ }^{3}$ Maternal complications are increase incidence of operative delivery, third and fourth degree perineal lacerations and postpartum infection, postpartum haemorrhage. ${ }^{4}$

In order to avoid the complications associated with delivery of macrosomic foetuses, it is essential to predict macrosomia antenatally such that effort can be taken to provide a modified intrapartum care. The traditional technique is biometric estimation of fetal weight (EFW) using a number of parameters, most commonly biparietal diameter (BPD), abdominal circumference (AC) and femur length (FL). ${ }^{5}$ The macrosomic fetus has more marked development of this subcutaneous fat, particularly in cases with GDM. ${ }^{6}$

The aim of this study was to determine the measurement of three potential ultrasound markers, namely foetal umbilical cord thickness, foetal fat layer and interventricular septal thickness for prediction of foetal macrosomia in women with Gestational diabetes.

\section{METHODS}

All Antenatal women who visit Vinayaka Mission's Kirupananda Variyar Medical College and Hospital, Salem and who give consent for the study are examined clinically and are subjected to Transabdominal ultrasound for umbilical cord thickness, foetal fat layer and inerventricular septal thickness. In total 100 antenatal cases were included in the study and the study period was between April 2016-March 2017.

\section{Inclusion criteria}

Antenatal woman:

- Diagnosed as Gestational Diabetes mellitus either on Meal plan/Insulin

- Gestational age of more than 37 weeks

- Singleton pregnancy.

- Reliable dates confirmed by Dating scan

- Three vessel umbilical cord

\section{Exclusion criteria}

- Gestational age of less than 37 weeks.

- Multiple gestations.

- Non-diabetic / overt diabetic patient.
- Known case of IUGR.

- Anomalous baby.

Participants underwent a third trimester scan .Three extra measurements - Umbilical cord thickness, Foetal fat layer and Interventricular septal thickness were measured in addition to the normal examination. These measurements took not much of an extra time. The abdominal circumference and estimated foetal weight were part of routine scan. Foetal anthropometric parameters, biparietal diameter (BPD), abdominal circumference (AC) and femur length (FL), were measured in all foetuses. EFW was obtained using the formula proposed by Hadlock et al.

\section{Cord thickness}

The sonographic cross sectional areas of the umbilical cord were measured in a free loop of umbilical cord. Using the umbilical cord diameter the umbilical cord area was calculated using computer software.

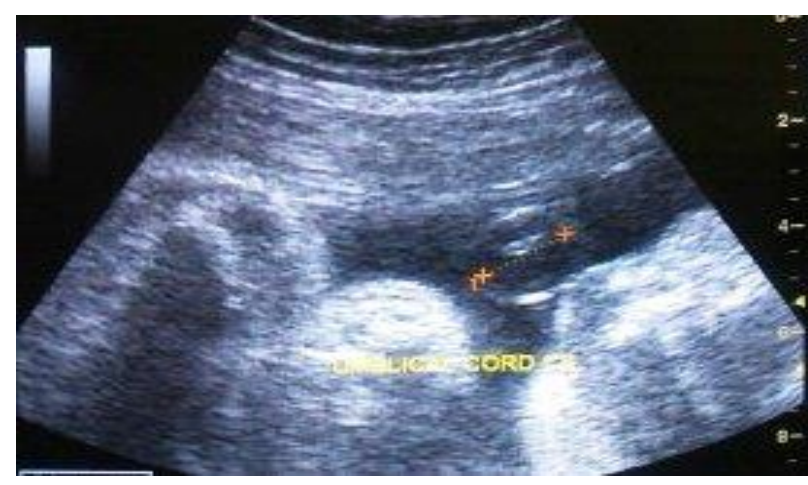

Figure 1: Umbilical cord cross section-measurement of cord diameter.

\section{Fetal fat layer}

The AC plane was magnified such that AC was completely focused in the screen area. The measurement of vertical distance between the inner and the outer border of the echogenic subcutaneous fat of abdomen is measured. Measurements were avoided in the quadrant which included the foetal back.

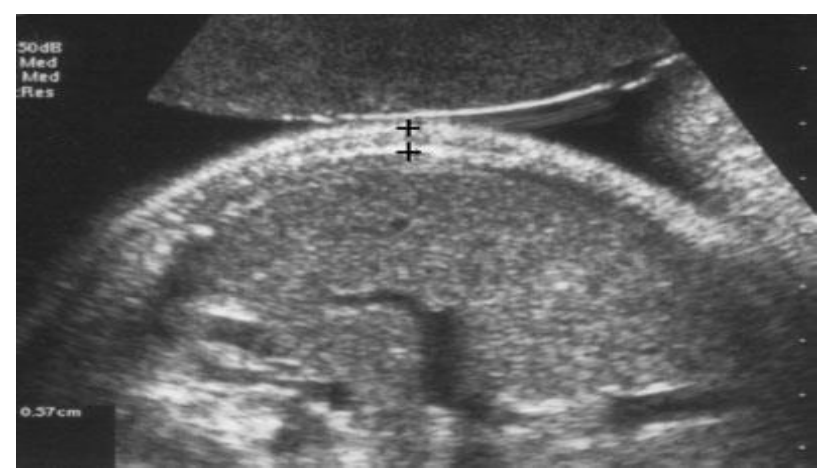

Figure 2: Measurement of fetal fat layer. 


\section{Interventricular septal thickness}

A four-chamber view was obtained; the septum was positioned horizontally (in order to use the axial plane for measurement). The midpoint of IVS (halfway between the apex and the mitral valve) was selected and cineloop was used to obtain the image of maximum ventricular filling (the smallest measurement). The image was optimized by using adequate magnification (heart approximately half of screen) and low dynamic range (compression).

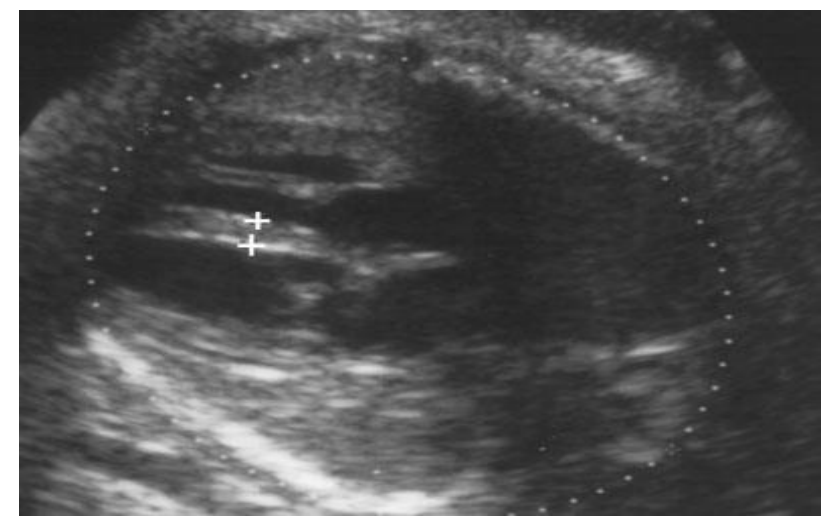

Figure 3: Measurement of the interventricular septum thickness.

All the above three measurements was performed three times at the same occasion, and the average of the three values was compared with the estimated fetal weight for its ability to predict macrosomia. After delivery, the newborn's body weight was assessed.

Further, the patients were followed up at delivery. The delivery details and baby details were filled up in the proforma after the delivery.

\section{RESULTS}

Data were obtained from a third-trimester scan of 100 patients. Forty patients were already taking insulin by the time of the scan and 60 were using diet alone. Table 1 gives the sensitivity, specificity and the positive predictive value for the parameters FFL, IVS and UC thickness for the diagnosis of macrosomia at term.

\section{Umbilical cord thickness (UC)}

Among 33 patients with umbilical cord thickness above $\geq 2.75 \mathrm{~mm}, 17$ patients delivered macrosomic foetus (PPV- 51.5\%). Among 67 patients with umbilical cord thickness above $2.75 \mathrm{~mm}, 2$ patients delivered macrosomic foetus (NPV-97.0\%). Among 19 patients who delivered macrosomic foetus, 17 patients had umbilical cord thickness $\geq 2.75 \mathrm{~mm}$ (sensitivity-89.5\%). Among 81 patients who delivered non-macrosomic foetus, 65 patients had umbilical cord thickness less than $2.75 \mathrm{~mm}$ (specificity $-80.2 \%$ ).

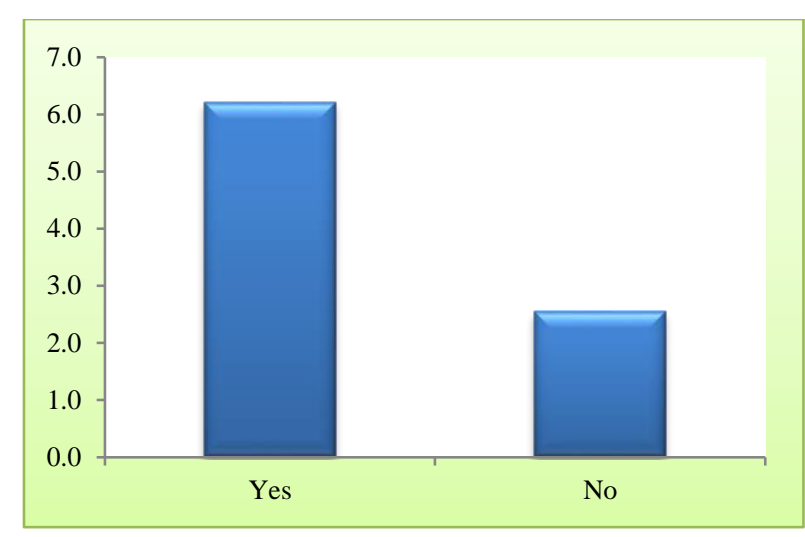

Figure 4: Macrosomia associated with umbilical cord thickness.

\section{Foetal fat layer}

Among 27 patients with foetal fat layer $\geq 4.5 \mathrm{~mm}, 16$ patients delivered macrosomic foetus (PPV-59.3\%). Among 73 patients with foetal fat layer $<4.5 \mathrm{~mm}, 3$ patients delivered nonmacrosomic foetus (NPV-95.9\%). Among 19 patients who delivered macrosomic foetus, 16 patients had foetal fat layer $\geq 4.5 \mathrm{~mm}$ (sensitivity-84.2\%). Among 81 patients who delivered non-macrosomic foetus, 70 patients had foetal fat layer $<4.5 \mathrm{~mm}$ (specificity-86.4\%).

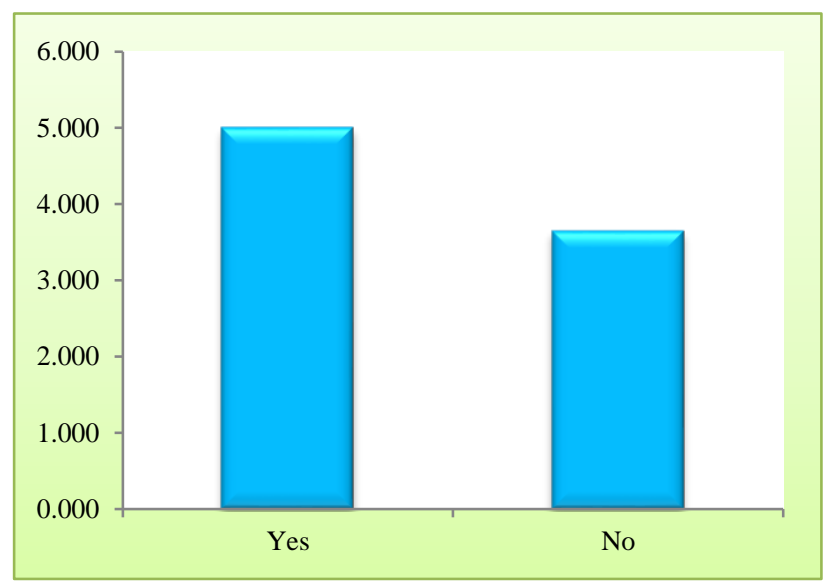

Figure 5: Macrosomia associated with foetal fat layer.

\section{Interventricular septal thickness}

Among 45patients with Interventricular septal thickness $\geq 3.9 \mathrm{~mm}, 16$ patients delivered macrosomic foetus (PPV$35.6 \%)$. Among 55 patients with Interventricular septal thickness $<3.9 \mathrm{~mm}, 52$ patients delivered non macrosomic foetus (NPV-95.9\%). Among 19 patients who delivered macrosomic foetus, 16 patients had Interventricular septal thickness $\geq 3.9 \mathrm{~mm}$ (sensitivity$84.2 \%)$. Among 81 patients who delivered nonmacrosomic foetus, 52 patients had Interventricular septal thickness $<3.9 \mathrm{~mm}$ (specificity-64.2\%). 
Table 1: Performance of umbilical cord thickness, foetal fat layer, interventricular septum thickness in the prediction of macrosomia at term.

\begin{tabular}{|lllll|}
\hline Parameter & Sensitivity & Specificity & Positive predictive value & Negative predictive value \\
\hline $\begin{array}{l}\text { Umbilical cord thickness } \\
\geq 2.75 \mathrm{~mm}\end{array}$ & $89.5 \%$ & $80.2 \%$ & $51.5 \%$ & $97.0 \%$ \\
\hline Foetal fat layer $\geq 4.5 \mathrm{~mm}$ & $84.2 \%$ & $86.4 \%$ & $59.3 \%$ & $95.9 \%$ \\
\hline $\begin{array}{l}\text { Interventricular septal } \\
\text { thickness } \geq 3.9 \mathrm{~mm}\end{array}$ & $84.2 \%$ & $64.2 \%$ & $35.6 \%$ & $95.9 \%$ \\
\hline
\end{tabular}

\section{Body mass index (BMI) with Macrosomia}

Among the 19 patients who delivered macrosomic fetus, $10(52.6 \%)$ i.e. majority were overweight.

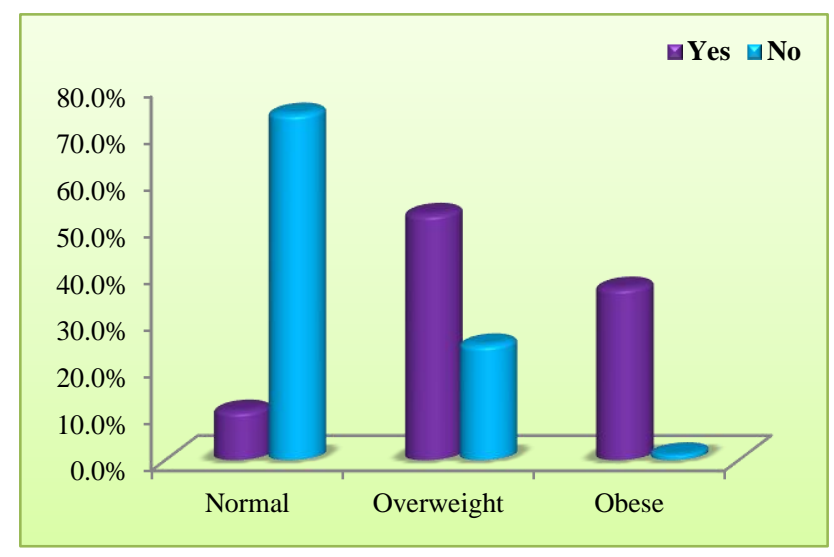

Figure 6: BMI with Macrosomia.

$\mathrm{P}$ value is 0.005 , statistically significant.62 patients belonged to normal BMI (19- 24.9) group. Among them, 2 patients delivered macrosomic foetus $(10.5 \%)$ and 60 patients delivered non-macrosomic patients $(74.1 \%) .30$ patients belonged to over-weight (BMI 25-29.9) group. Among them, 10 patients delivered macrosomic foetus $(52.6 \% \%)$ and 20 patients delivered nonmacrosomic foetus $(24.7 \%) .8$ patients belonged to obese $(\mathrm{BMI} \geq 30)$ group. Among them, 7 patients delivered macrosomic foetus $(36.8 \%)$ and one patients delivered nonmacrosomic foetus (1.2\%). Thus, as the BMI increases, the chance that a patient will deliver a macrosomic foetus increases.

\section{DISCUSSION}

In pregnancies complicated by diabetes mellitus, foetal macrosomia is common. Macrosomia increases the risk of shoulder dystocia, brachial plexus injury, clavicular fractures, and increases the rate of admissions to the neonatal intensive care unit. For the mother the risks associated with macrosomia are caesarean delivery, postpartum haemorrhage and perineal lacerations; Antenatal prediction of macrosomia helps in identifying the population at highest risk for complications. Several studies of ultrasound measurement for predicting of foetal macrosomia were established. In present study we evaluated the usefulness of sonographic measurement of foetal fat layer, umbilical cord thickness and interventricular septal thickness as predictors of macrosomia in gestational diabetes mellitus.

\section{Ultrasound measurements}

\section{Umbilical cord thickness}

In present study umbilical cord thickness had low positive predictive value, but good sensitivity and negative predictive value. Hence, if umbilical cord thickness is less than 90th centile the chance of macrosomia is less. Cromi et al reported that the proportion of cases with large umbilical cord was significantly higher in the group of macrosomic compared to non macrosomic infants $(54.7 \%$ vs $8.7 \%) .^{7}$

\section{Fetal fat layer}

In present study the cut off of foetal fat layer $\geq 5 \mathrm{~mm}$ as predictor of macrosomia had sensitivity of $84.2 \%$ and specificity of $86.4 \%$. Thus, foetal fat layer $\geq 5 \mathrm{~mm}$ is a reliable predictor of macrosomia. Bethune $\mathrm{M}$ et al reported that fetal fat layer $\geq 5 \mathrm{~mm}$ was the most useful predictor of macrosomia at term. He reported that the risk of macrosomia increases tenfold when foetal fat layer $\geq 5$ mm. ${ }^{7}$

\section{Interventricular septal thickness}

In present study a cut off of Interventricular septal thickness $\geq 3.9 \mathrm{~mm}$ as a predictor of macrosomia had sensitivity of $84.2 \%$, specificity of $64.2 \%$, and negative predictive value of $95.9 \%$. Thus, interventricular septal thickness $\geq 3.9 \mathrm{~mm}$ is a reliable predictor of macrosomia. Bethune et al reported that sonographic measurement of interventricular septal thickness positively correlated well with new born weight. In their study IVS thickness $\geq 4$ $\mathrm{mm}$ had sensitivity of $82 \%$, specificity of $22 \%$ and with IVS thickness $\geq 5 \mathrm{~mm}$ had sensitivity of $53 \%$ and specificity of $87 \% .^{8}$

\section{$B M I$}

In present study among 19 patients who delivered macrosomic babies, $52.6 \%$ had $\mathrm{BMI} \geq 26$. In group with 
BMI $\geq 30$ about $36.8 \%$ delivered macrosomic babies. Thus, maternal BMI has significant association with macrosomia. C.tian et al reported that excessive gestational weight gain might increase the risk of macrosomia. ${ }^{9}$ Karim et al reported that post maturity was associated with macrosomia. ${ }^{10}$

\section{CONCLUSION}

Macrosomia is a cause of the worst of obstetric emergencies such as shoulder dystocia, birth asphyxia, and postpartum haemorrhage. Shoulder dystocia cannot always be predicted accurately. However, predicting macrosomia can help to identify the population at risk of such complications. Several studies of sonographic measurement for predicting of foetal macrosomia were established. Umbilical cord thickness, foetal fat layer and Interventricular septal thickness are good predictors of foetal macrosomia. In the assessment of risk of macrosomia in addition to the ultrasonographic measurements the clinical risk factors must be considered. Further studies are needed to evaluate the clinical value of incorporating these soft tissue measurements in formulas for estimation of foetal weight.

Funding: No funding sources

Conflict of interest: None declared

Ethical approval: Not required

\section{REFERENCES}

1. Wild S, Roglic G, Green A, King H. Global prevalence of diabetes: Estimates for the year 2000 and projections for 2030. Diabetes Care. 2004 May;27(5):1047-53.

2. Ian Donald's Practical Obstetric problems. seventh ed. Diabetes. 2014;7:127.

3. Spellacy WN, Miller S, Winegar A, Peterson PQ. Macrosomia maternal characteristics and infant complications. Obstet Gynecol. 1985;66:158-61.
4. Ferber A. Maternal complications of fetal macrosomia. Clin Obstet Gynecol. 2000;43:335-9.

5. Hadlock FP, Harrist RB, Sharman RS, Deter RL, Park SK. Estimation of fetal weight with the use of head, body and femur measurements. A prospective study. Am J Obstet Gynecol. 1985;151:333-7.

6. Brans YW, Shannon DL, Hunter MA. Maternal diabetes and neonatal macrosomia. II. Neonatal anthropometric measurements Early Hum Dev. 1983; 8:297-305.

7. Cromi A, Ghezzi F, Di Naro E, Siesto G, Bergamini $\mathrm{V}$, Raio L. Large cross-sectional area of the umbilical cord as a predictor of fetal macrosomia. Ultrasound Obstet Gynecol. 2007 Nov;30(6):861-6.

8. Bethune M, Bell R. Evaluation of the measurement of the fetal fat layer, interventricular septum and abdominal circumference percentile in the prediction of macrosomia in pregnancies affected by gestational diabetes. Ultrasound Obstet Gynecol. 2003;22:58690 .

9. Tian $\mathrm{C}, \mathrm{Hu} \mathrm{C}, \mathrm{He} \mathrm{X}, \mathrm{Zhu} \mathrm{M}$, Qin F, Liu Y, Hu C. Excessive weight gain during pregnancy and risk of macrosomia: a meta-analysis. Arch Gynecol Obstet. 2016 Jan;293(1):29-35.

10. Karim SA, Mastoor M, Ahmed AJ. Macrosomia: maternal and fetal outcome. Asia Oceania J Obstet Gynaecol. 1994;20(1):73-6.

Cite this article as: Janani N, Vimala D, Gayathri N. Prospective study on sonographic measurement of umbilical cord thickness, foetal fat layer, interventricular septal thickness as predictors of macrosomia in fetus of women with gestational diabetes mellitus. Int J Reprod Contracept Obstet Gynecol 2018;7:1997-2001. 